\title{
Cell death induced by dexamethasone in lymphoid leukemia is mediated through initiation of autophagy
}

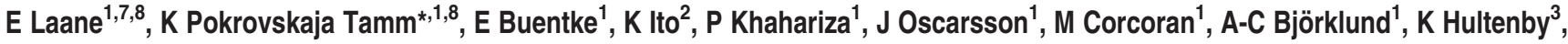 \\ J Lundin ${ }^{1}$, M Heyman ${ }^{4}$, S Söderhäll ${ }^{4}$, J Mazur ${ }^{5}$, A Porwit ${ }^{1}$, PP Pandolfi ${ }^{2}$, B Zhivotovsky ${ }^{6}$, T Panaretakis ${ }^{1,8}$ and D Grandér ${ }^{1,8}$
}

Glucocorticoids are fundamental drugs used in the treatment of lymphoid malignancies with apoptotic cell death as the hitherto proposed mechanism of action. Recent studies, however, showed that an alternative mode of cell death, autophagy, is involved in the response to anticancer drugs. The specific role of autophagy and its relationship to apoptosis remains, nevertheless, controversial: it can either lead to cell survival or can function in cell death. We show that dexamethasone induced autophagy upstream of apoptosis in acute lymphoblastic leukemia cells. Inhibition of autophagy by siRNA-mediated repression of Beclin 1 expression inhibited apoptosis showing an important role of autophagy in dexamethasone-induced cell death. Dexamethasone treatment caused an upregulation of promyelocytic leukemia protein, PML, its complex formation with protein kinase B or Akt and a PML-dependent Akt dephosphorylation. Initiation of autophagy and the onset of apoptosis were both dependent on these events. PML knockout thymocytes were resistant to dexamethasone-induced death and upregulation of PML correlated with the ability of dexamethasone to kill primary leukemic cells. Our data reveal key mechanisms of dexamethasone-induced cell death that may inform the development of improved treatment protocols for lymphoid malignancies.

Cell Death and Differentiation (2009) 16, 1018-1029; doi:10.1038/cdd.2009.46; published online 24 April 2009

Glucocorticoids (GCs) have been used as important therapeutic agents in the treatment of acute lymphoblastic leukemia (ALL) and other lymphoid malignancies for more than 50 years. ${ }^{1,2}$ In vivo and ex vivo GC sensitivity is furthermore a major prognostic factor in childhood ALL. ${ }^{3,4}$ Despite extensive clinical use and research, the molecular mechanisms of GC action remain elusive. The effect of GCs on lymphoid cells is dramatic and includes $\mathrm{G} 1$ phase cell cycle arrest and apoptosis. This induction of apoptosis has also been proposed to be the main effector mechanism for the beneficial effects of GC treatment in lymphoid malignancies. ${ }^{5}$ Evidence is accumulating that non-apoptotic programmed cell death (PCD), such as mitotic catastrophe, senescence, necrosis-like PCD and autophagy, may also play a role in the tumor response to anticancer drugs. ${ }^{6,7}$ Autophagy is a well-conserved process, regulating normal cytoplasmic and organelle turnover, and is characterized by the formation of autophagosomes: double- or multiple-membrane-surrounded cytoplasmic vesicles engulfing cytoplasmic organelles such as mitochondria and endoplasmic reticulum. Subsequently, autophagosomes fuse with lysosomes and their contents are degraded by the lysosomal enzymes. ${ }^{6}$ Although the process of autophagy was initially described as a survival strategy in times of nutrient limitation, it may, however, also lead to $P C D$, presumably by an excessive activation of this selfdegrading system. ${ }^{6,8}$

Autophagic vesicle formation is dependent on protein complexes including Atg6/Beclin $1^{6,9}$ and the class III phosphatidylinositol 3-kinase (PI3KIII). ${ }^{10}$ In contrast, signaling through the class I PI3K/Akt pathway functions as a negative upstream regulator of autophagy. ${ }^{11}$ This pathway is stimulated in the presence of nutrients and growth factors. A recent study has shown that the PML protein is involved in negative regulation of $\mathrm{PI} 3 \mathrm{~K}$ signaling through dephosphorylation of Akt. ${ }^{12}$ PML protein forms nuclear bodies or PML oncogenic domains, PODs; PML and PODs have been implicated in the negative regulation of cell proliferation, protein degradation and apoptosis. ${ }^{13,14}$ Multiple proapoptotic signals have been shown to be dependent on PML, including caspase-independent cell death. ${ }^{15,16}$ The role of PML in Dex-induced cell death or in the induction of autophagy has, however, not been described earlier.

In this study we show that Dex-induced cell death in lymphoid cells involves induction of autophagy before the onset of apoptosis and that PML upregulation and Akt dephosphorylation is required for these processes. GCs are

\footnotetext{
${ }^{1}$ Department of Oncology and Pathology, Cancer Centre Karolinska R8:03, Karolinska Institutet and Karolinska University Hospital, Stockholm S-171 76, Sweden; ${ }^{2}$ Department of Pathology, Beth Israel Deaconess Medical Center, 77 Ave Louis Pasteur, Boston, MA 02115, USA; ${ }^{3}$ Clinical Research Center, Karolinska Institutet and Karolinska University Hospital, Huddinge 14186 , Sweden; ${ }^{4}$ Childhood Cancer Research Unit, Department of Women and Child Health, Astrid Lindgren Children's Hospital, Stockholm 171 76, Sweden; ${ }^{5}$ Institute of Mother and Child, Warsaw, ul. Kasprzaka 17a, Warsaw 01-211, Poland and ${ }^{6}$ Institute of Environmental Medicine, Karolinska Institutet, Stockholm 171 77, Sweden

*Corresponding author: KP Tamm, Department of Oncology and Pathology, Cancer Centre Karolinska, Karolinska Institutet and Karolinska University Hospital, Stockholm S-171 76, Sweden. Tel: + 46(8)51779394; Fax: + 46(8)339031; E-mail: katja.pokrovskaja@ki.se

${ }^{7}$ Current address: Divison of Hematology, Internal Medicine Clinic, North Estonian Regional Hospital, J Sutiste tee 19, Tallinn 13419, Estonia

${ }^{8}$ These authors contributed equally to this work.

Keywords: dexamethasone; apoptosis; autophagy; leukemia; PML

Abbreviations: GCs, glucocorticoids; ALL, acute lymphoblastic leukemia; PCD, apoptotic programmed cell death; PI3KIII, class III phosphatidylinositol 3-kinase Received 06.6.08; revised 05.3.09; accepted 17.3.09; Edited by H-U Simon; published online 24.4.09
} 
important drugs in the treatment of lymphoid leukemias as well as for the stratification of patients with leukemia. Thus, the sensitivity to GCs is likely to reflect certain features of cancer cells such as, for example, expression of resistance genes. Therefore, revealing novel mechanisms underlying GC-induced cell death may help uncover reasons for the sensitivity/resistance to a variety of other drugs and will facilitate the future design of optimized therapies in lymphoid malignancies.

\section{Results}

Dex induces autophagy. We have earlier shown that Dexinduced cell death in ALL cell lines and primary lymphoblasts of ALL patients is mediated through the mitochondrial apoptotic pathway associated with the activation of Bak and $\mathrm{Bax}$, downregulation of $\mathrm{Bcl}-2$ and $\mathrm{Bcl}-\mathrm{xL}$, loss of mitochondrial membrane potential $(\Delta \Psi \mathrm{m})$, caspase activation, loss of propidium iodide (PI) exclusion and exposure of phosphatidylserine on the plasma membrane. ${ }^{17}$ Figure $1 \mathrm{~A}$ represents a typical analysis of apoptosis induced by Dex in ALL cell lines: two - sensitive, RS4;11 and SUP-B15, and one - resistant, Reh cells. As the upstream signaling leading to apoptosis induced by Dex is largely unknown, we investi- gated the morphological characteristics of Dex-induced cell death using electron microscopy.

RS4; 11 cells were cultured for 24 and $36 \mathrm{~h}$ in the absence or presence of $100 \mathrm{nM}$ Dex and subjected to electron microscopy (Figure 1B). In Dex-treated cells, vacuoles surrounded by a double membrane, a characteristic of autophagosomes ${ }^{6}$ (Figure 1C, arrows), appeared at $24 \mathrm{~h}$ post-treatment and contained membrane structures and/or parts of endoplasmic reticulum or bulk of cytoplasm. Many of the vesicles were in close contact with mitochondria (Figure 1C, arrowheads). Apart from the appearance of autophagosomes, the nucleus and the cell morphology were initially intact, indicating that the formation of autophagosomes precedes the execution of cell death.

Microtubule-associated protein light chain 3, LC3, is now widely used to monitor autophagy by studying its translocation to the autophagosomes and by detecting conversion of LC3-I to LC3-II, which is the form localized to the autophagosomal membranes. ${ }^{18,19}$ RS4;11 cells were transfected with GFP. $\mathrm{LC}^{18}$ and $24 \mathrm{~h}$ later treated with Dex for another $24 \mathrm{~h}$. Dextreatment induced GFP-LC3 translocation in 90\% of the GFP-LC3-positive cells from a diffuse cytosolic localization to a distinct punctate pattern, as did amino-acid starvation, a known inducer of autophagy (Figure 2a). To measure the total amounts of LC3-II, which is known to correlate well with the
A
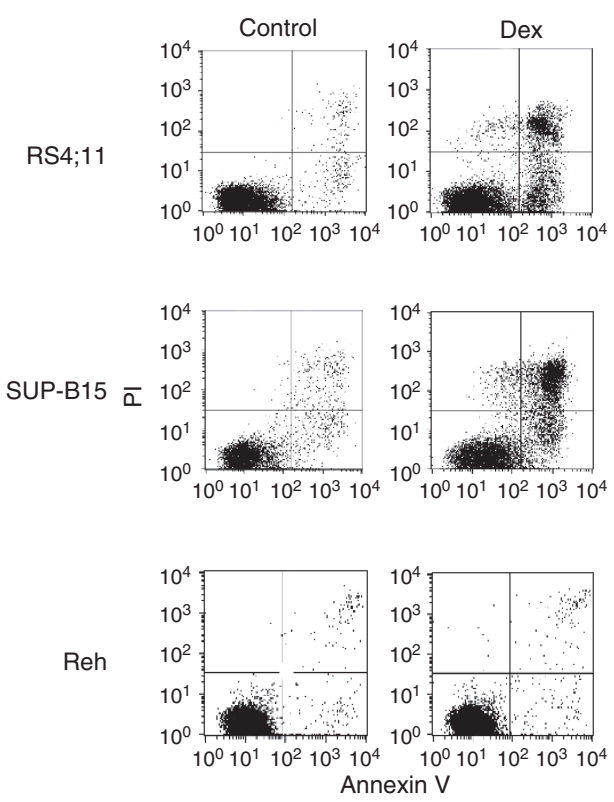

B
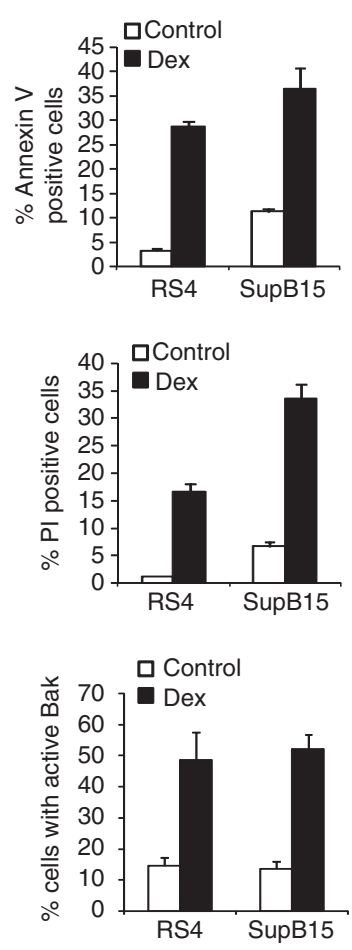

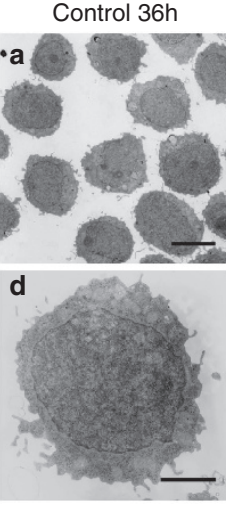

C
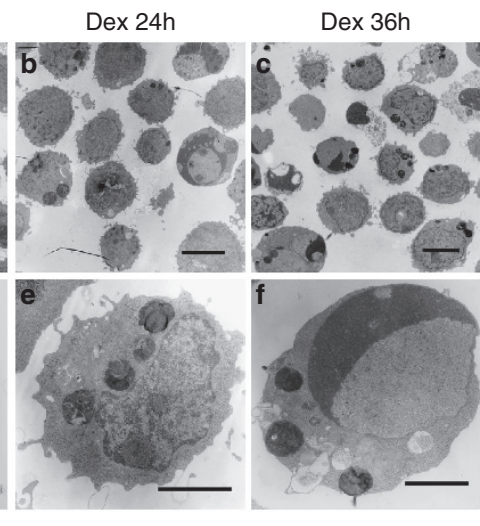

Dex 36h

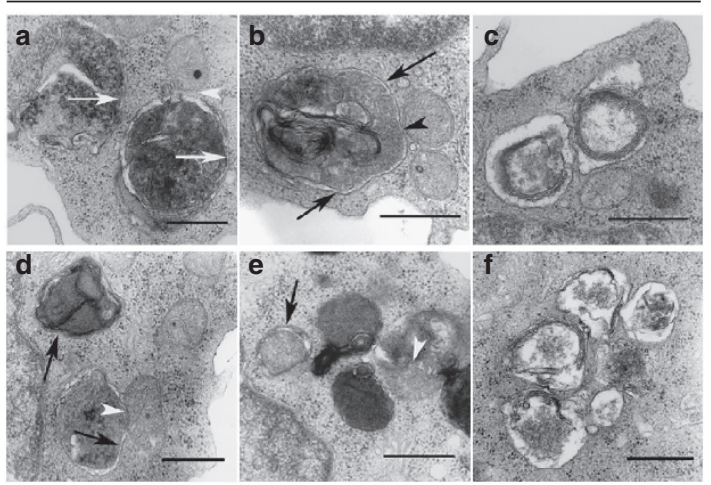

Figure 1 Dexamethasone induced apoptosis and autophagy in ALL cell lines. (A) RS4;11, SUP-B15 and Reh cells were left either untreated or treated with $100 \mathrm{nM}$ of Dex for $48 \mathrm{~h}$, stained for Annexin V/PI and analyzed by flow cytometry. The percentage of RS4;11 and SupB15 cells positive for annexin V staining, PI and active Bak are presented in the bar charts $(n=3)$. (B) RS4;11 cells were either left untreated (control) or were treated with $100 \mathrm{nM}$ Dex for 24 or $36 \mathrm{~h}$, as indicated. Electron microphotographs were taken at low (upper panel) or high (lower panel) magnification. $\mathrm{Bar}=0.5 \mu \mathrm{M}(n=2)$. (C) High resolution electron micrographs. The double membrane-surrounded autophagosomes (arrows) contain cell components. Many autophagosomes were in close contact with mitochondria (white and black arrowheads). Bar $=0.5 \mu \mathrm{M}$. Control cells were incubated in culture without Dex for $36 \mathrm{~h}$. No vehicle treatment was required as Dex (Oradexon) is supplied in water solution 
a

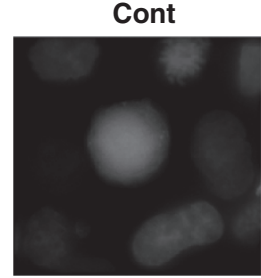

b

SUP-B15

RS4;11 starv 2 h

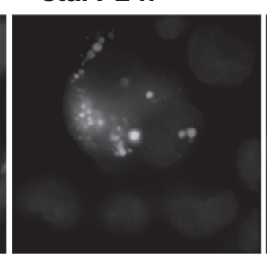

Dex $24 \mathrm{~h}$

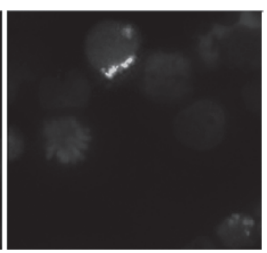

C
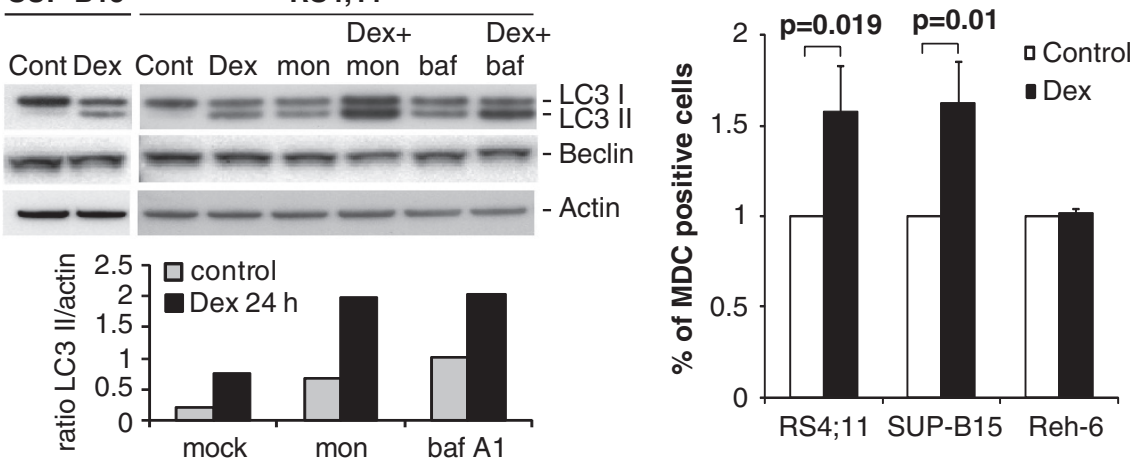

RS4;11 SUP-B15 Reh-6

d

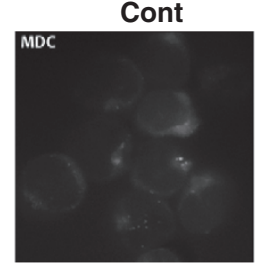

Dex 24h

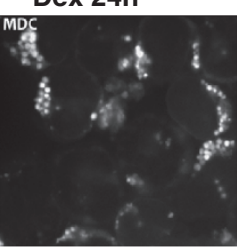

e

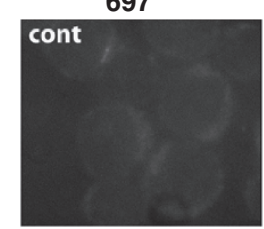

CLL resist

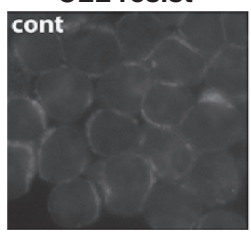

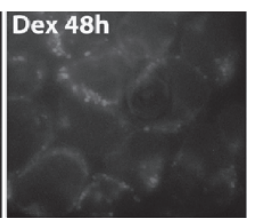

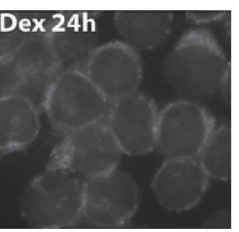

Dex 24h

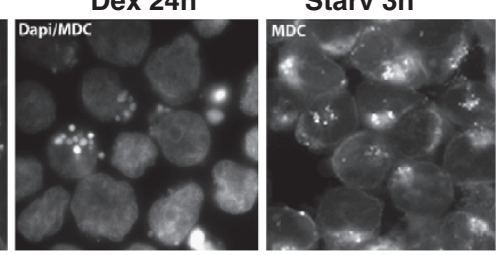

ALL

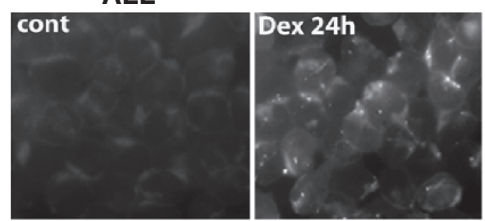

CLL sens
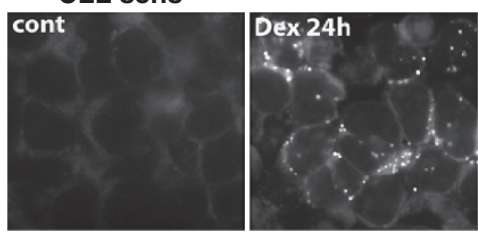

Figure 2 Dex induced LC3 conversion, GFP-LC3 translocation and MDC-positive staining in ALL cells. (a) RS4;11 cells were transfected with a GFP-LC3 plasmid before treatment with Dex for $24 \mathrm{~h}$ or amino-acid starvation for $2 \mathrm{~h}$ (starv). Note GFP-LC3 translocation from a diffuse to a dotty pattern indicating LC3 recruitment to autophagosome membranes $(n=3)$. (b) SUP-B15 and RS4;11 cells were treated with $100 \mathrm{nM}$ Dex for $24 \mathrm{~h}$ followed by either $10 \mu \mathrm{M}$ monensin (mon) or $100 \mathrm{nM}$ Bafilomycin A1 (bafA1) for $1.5 \mathrm{~h}$ (shown only for RS4;11) and total cell lysates were subjected to western blotting using anti-LC3 and Beclin antibodies. The bands' intensities were quantified using Image Gauge and presented as ratio between LC3-II and $\hat{a}$-actin $(n=2)$. (c) Indicated cell lines were treated with $100 \mathrm{nM}$ Dex for $24 \mathrm{~h}$, stained with MDC and analyzed by flow cytometry. Bar chart represents an increase in mean fluorescent intensity, MFI, of MDC staining $(n=3)$. (d) MDC or MDC/DAPI staining of RS4 cells as recorded by microscopy. Amino-acid starvation for $3 \mathrm{~h}$ was used to induce autophagy as positive control. (e) MDC staining of $697 \mathrm{ALL}$ cells, primary cells from an ALL patient, primary cells from two CLL patients (resistant and sensitive to Dex) that were either left untreated (cont) or were treated for indicated times with Dex as described in Materials and Methods section. The images were recorded on a Zeiss Axioplan-2 microscope and Axiovision software 4.1. A UV filter with excitation $350 \pm 50 \mathrm{~nm}$ and emission $420 \mathrm{~nm}$ was used for detection of MDC staining $(n=3)$

number of autophagosomes, ${ }^{19}$ we performed immunoblotting using anti-LC3 antibodies. Dex-treatment of SupB15 and RS4;11 for 16 and $24 \mathrm{~h}$, respectively, induced a readily detectable conversion from LC3-I to LC3-II (Figure 2b). However, as LC3-II is itself degraded by autophagy, it is important to compare the levels of LC3-II in the absence or presence of lysosomal inhibitors. ${ }^{19,20}$ Incubation of cells with lysosomal inhibitors that alter the lysosomal $\mathrm{pH}$ thus preventing maturation of autophagic vacuoles, ${ }^{21}$ monensin or bafilomycin A1 alone, led to the accumulation of autophagosomes, 
manifested by the appearance of an LC3-II band, indicating that a certain basal level of autophagy occurs in these cells (Figure $2 b$ ). In the presence of Dex the amount of LC3-II increased above the levels induced by either inhibitor alone (Figure $2 \mathrm{~b}$, western), as estimated by quantifying the autophagy-associated LC3-II bands in relation to the total protein levels (Figure $2 b$, bar chart). It can be concluded from this experiment that Dex-induced accumulation of autophagosomes was a result of an enhanced formation of autophagosomes and not of a decreased degradation of spontaneously forming autophagosomes. We next used monodansylcadaverine, MDC, a dye, which stains autophagolysosomes. ${ }^{20}$ Although MDC does not specifically stain autophagosomes, it can be used for quantification of autophagy in some systems when a correlation with other autophagy markers is established. ${ }^{22}$ Cells were analyzed by flow cytometry (Figure 2c) and microscopy (Figure 2d). MDC staining increased at 16 and $24 \mathrm{~h}$ in Dex-sensitive RS4;11 and SUP-B15 cells but not in Dex-resistant Reh cells (data not shown and Figure 2c). Amino acid starvation-induced autophagy as measured by MDC staining was induced in all cell lines, showing that the Dex-resistant Reh cells were not deficient in their ability to undergo autophagy (data not shown). Dex- or amino acid starvation-induced MDC staining was blocked by 3-MA and LY294002 as well as by cycloheximide, drugs that inhibit autophagosome formation $^{20}$ (data not shown and Figure 4). Thus, induction of MDC-positive staining by Dex correlated well with the data obtained by electron microscopy, induction of LC3 conversion and the LC3 translocation. Therefore, we concluded that MDC staining can be used in our system to monitor autophagy. A DNA-damaging agent, doxorubicin that induced on average $40 \%$ of cell death in RS4;11 cells did not induce MDC-positive staining (data not shown) indicating that autophagy occurs in response to a specific signal. MDCpositive vacuoles were also detected after Dex exposure in another pre-B ALL cell line, 697 and in primary ex vivo lymphoblasts from two ALL patients (Figure 2e, upper panel). GCs are important drugs in the treatment of most of lymphoid malignancies including chronic lymphocytic leukemia, CLL. CLL is the most common lymphoid malignancy and samples from CLL patients are readily available for in vitro analysis. To test whether the autophagic response to Dex is a more general phenomenon, ex vivo cells from 11 CLL patients were treated with $10 \mathrm{nM}$ of $\mathrm{Dex}^{23}$ and induction of autophagy and cell death was monitored. Nine out of the $11 \mathrm{CLL}$ samples were sensitive to Dex-induced apoptosis (data not shown and Figure 6b-d). Importantly, MDC-positive staining was detected in nine Dex-sensitive and not in the Dex-resistant samples (Figure 2e, representative figure for one resistant and one sensitive sample is shown).

Electron microscopy and LC3 immunoblotting showed that Dex-induced autophagy occurs before massive apoptosis. Indeed, co-staining using MDC and DAPI showed that Dex-induced MDC-positive vacuoles were present in cells with intact nuclei, before the nuclear fragmentation, one of the hallmarks of apoptosis had occurred (Figure 2d). To substantiate these data, RS4;11 cells were transfected with GFP-LC3 and treated with Dex for $24 \mathrm{~h}$. Figure 3a shows that all the cells with translocated GFP-LC3 have intact, noncondensed nuclei, thus, providing a confirmation that
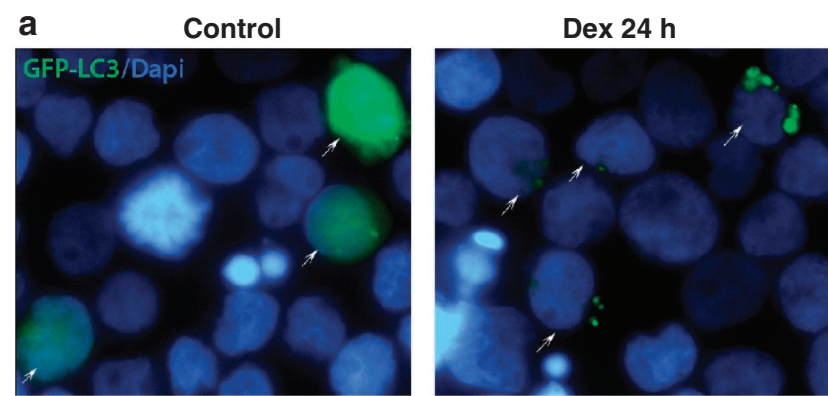

b

Control

Dex $24 \mathrm{~h}$
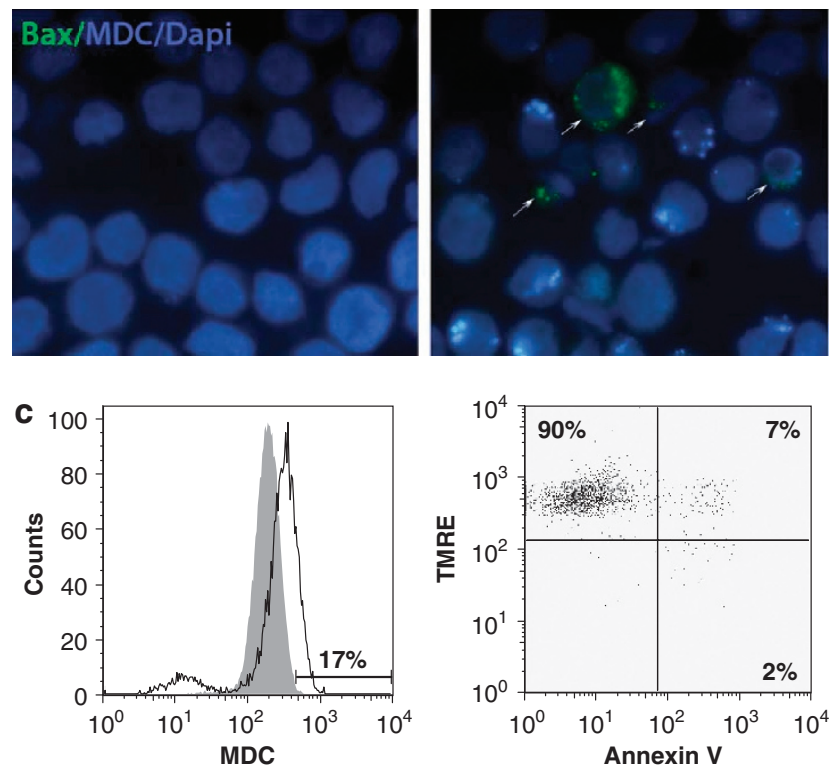

Figure 3 The formation of autophagic vacuoles in response to Dex precedes activation of Bax and apoptosis. (a) RS4;11 cells were transfected with GFP-LC3 (green) and either left untreated (control) or were treated with Dex for $24 \mathrm{~h}$. Cells were then fixed, stained with DAPI and analyzed by fluorescent microscopy. Arrows point at the GFP-LC3-positive cells with diffuse pattern in control and punctuated pattern in Dex-treated cells $(n=2)$. (b) RS4;11 cells were treated with Dex for $24 \mathrm{~h}$ and stained with Dapi (Blue), Bax (green) and MDC (blue). Arrows point at Baxpositive cells that were all negative for MDC-stained vacuoles. DAPI was diluted 10fold to match the fluorescence intensity of MDC staining. A UV filter with excitation $350 \pm 50 \mathrm{~nm}$ and emission $420 \mathrm{~nm}$ was used for detection of MDC and the DAPI staining ( $n=2)$. (c) Triple staining of RS4;11 cells with MDC, annexin V and TMRE. The $100 \mathrm{nM}$ Dex-treated for $24 \mathrm{~h}$ cells with high MDC staining were gated $(17 \%$, histogram) and the Annexin V/TMRE profile of these cells was analyzed (dot plot). MDC-positive cells were Annexin V negative/TMRE positive $(n=2)$

autophagy is initiated before apoptosis. We reported earlier that activated Bax was detected in Dex-induced apoptotic cells with fragmented nuclei. ${ }^{17}$ Indeed, cells with MDCpositive autophagosomes were not Bax-positive, again indicating that the features of apoptosis are later events in Dex-induced cell death (Figure $3 b$ ). Finally, triple staining for MDC/Annexin V/TMRE of Dex-treated cells indicated that the MDC-high cell population consisted of TMRE-positive/Annexin V-negative cells (Figure $3 c$ ), providing additional evidence that autophagy precedes the manifestation of apoptosis.

Inhibition of the PI3KIII complex reduces Dex-induced autophagy and cell death. Inhibitors of the PI3KIII 
complex, such as LY294002 and 3-MA, block the formation of autophagosomes. ${ }^{20,24}$ Addition of LY294002 before Dex inhibited Dex-induced autophagosome formation in RS4;11 cells as shown by MDC staining (Figure 4a). Ly294002 was not toxic to the cells and significantly protected from Dex-induced Annexin V-positivity and caspase-3 activation (data not shown and Figure 4b). Treatment with $5 \mathrm{mM}$ of 3-MA, the most commonly used pharmacological inhibitor of autophagy, for $3 \mathrm{~h}$ completely protected from amino acid starvation-induced MDC staining and LC3 conversion (data not shown). Treatment with 3-MA inhibited autophagosome formation induced by Dex as measured by LC3 conversion (Figure 4c). 3-MA also significantly protected from Dexinduced apoptosis in RS4;11 and SUP-B15 cells (Figure 4d, left and right chart, respectively). Thus, pharmacological inhibition of autophagy leads to the inhibition of Dex-induced apoptosis in ALL cell lines.

Beclin 1 is required for initiating the formation of autophagic vacuoles. ${ }^{25}$ Beclin 1 protein levels were not affected by treatment with Dex (Figure 2b). To confirm the role of autophagy in Dex-induced cell death, RS4;11 cells were transiently transfected with Beclin 1 siRNA followed by a
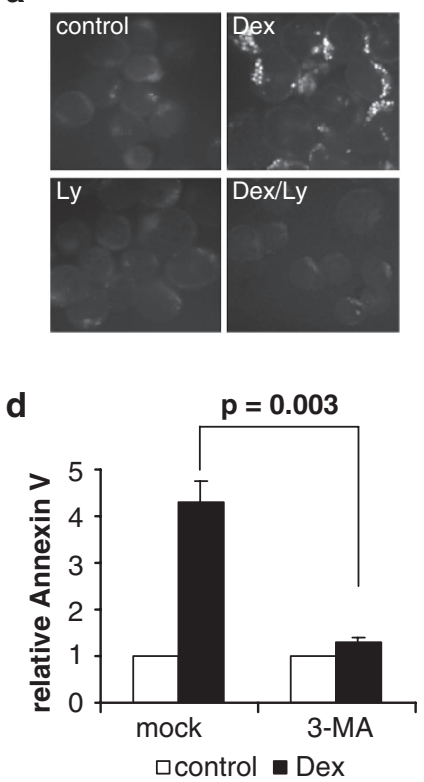

b

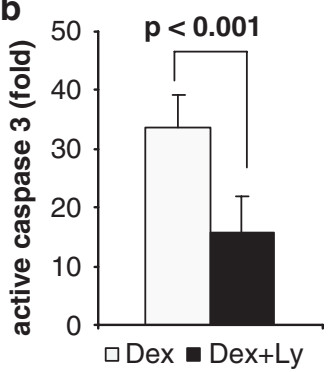

C
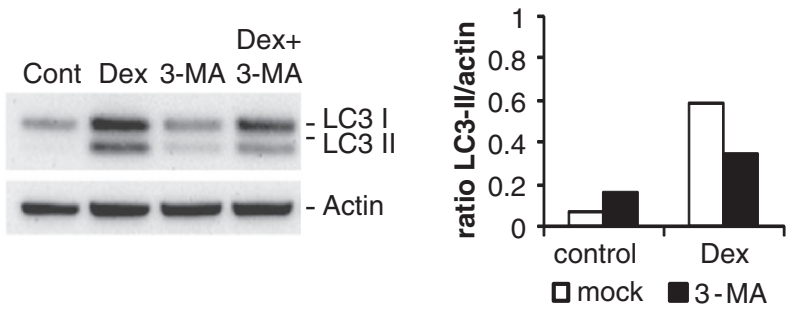

e

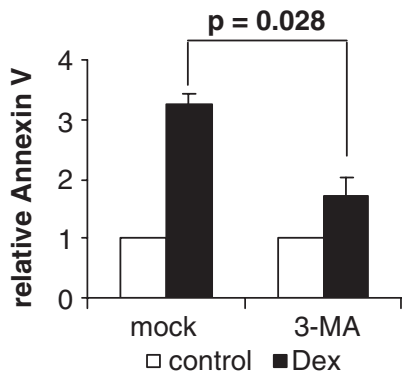

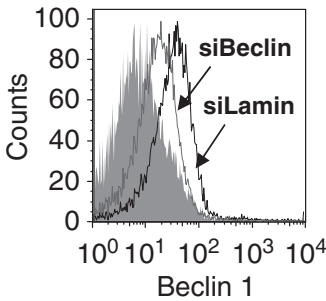

f

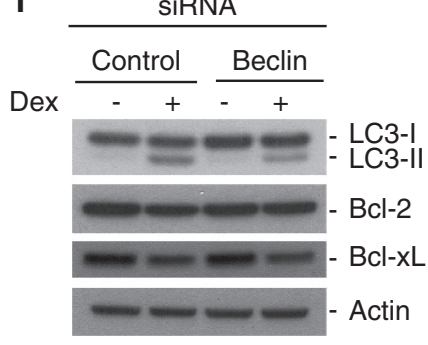

g

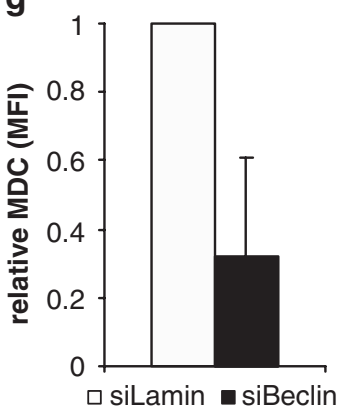

h

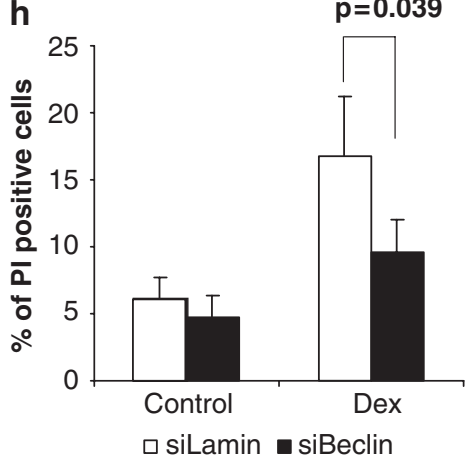

Figure 4 Inhibition of autophagy results in the reduction of cell death induced by Dex. (a, b) LY294002 inhibits autophagy and Dex-induced cell death. RS4;11 cells were treated with $100 \mathrm{nM}$ of Dex for $36 \mathrm{~h}$ in the absence or presence of the inhibitor of PI3 kinases, LY294002. Autophagy was assessed by MDC staining (a) and cell death was assessed by activation of caspase-3 measured as a ratio between treated and control samples $(n=3)(\mathbf{b})$. (c, d) 3-MA inhibits autophagy and cell death in RS4;11 and SUP. B15 cells. RS4;11 cells were treated with $100 \mathrm{nM}$ Dex for $24 \mathrm{~h}$ in the absence or presence of the inhibitor of class III PI3 kinases 3-MA, lysed and subjected to western blotting with anti-LC3 antibodies to monitor autophagy (c). The amounts of autophagy-specific LC3-II were calculated as a ratio between band intensities of LC3-II and $\alpha$-actin (c, bar chart). Cell death of RS4;11 and SUP-B15 cells at 36 and $24 \mathrm{~h}$, respectively, was assessed using Annexin V staining (d). The chart represents changes of Annexin V-positive cells relative to the corresponding controls $(n=3)$. $(\mathbf{e}, \mathbf{f}, \mathbf{g}, \mathbf{h})$ Decrease in Beclin 1 protein levels by siRNA inhibits Dex-induced autophagy and cell death. RS4;11 cells were co-transfected with GFP and increased doses of siRNA against Beclin 1 or Lamin and treated with $100 \mathrm{nM}$ Dex for $24 \mathrm{~h}$. Beclin 1 protein levels in total cell population was monitored by western blotting and by flow cytometry (histogram: gray - isotype control, black line - lamin siRNA, gray line - Beclin1 siRNA (e). RS4 cells transfected with either siBeclin or siLamin were treated with $100 \mathrm{nM}$ Dex for $24 \mathrm{~h}$ and LC3 conversion, Bcl2 and Bcl-xL protein levels were detected by western blotting (f). Autophagolysosome formation was assessed by MDC staining using flow cytometry. The bars represent a relative MFI of MDC staining in the indicated samples versus their corresponding controls. The value for silamin-transfected cells was set as 1. A mean of three independent experiments is shown with $P<0.001$ calculated from paired data (g). Cell death was assessed by PI staining in the GFP-positive gated cell population $(n=4)(\mathrm{h})$ 
treatment with Dex. Beclin 1 siRNA transfection led to a downregulation of Beclin 1 protein levels as assessed by western blotting and immunofluorescense staining (Figure 4e). It was recently shown that $\mathrm{Bcl}-2$ and $\mathrm{Bcl}-\mathrm{xL}$ interact with Beclin 1 and inhibit autophagy. ${ }^{26}$ Knockdown of Beclin 1 largely inhibited autophagy as shown by the conversion of LC3-I to LC3-II but had no effect on the Dex-induced regulation of the $\mathrm{Bcl}-2$ family members $\mathrm{Bcl}-2$ and $\mathrm{Bcl}-\mathrm{xL}$ (Figure 4f). In the Beclin 1 siRNA-transfected cells, the levels of autophagy measured by MDC staining were also reduced (Figure $4 \mathrm{~g}$ ) as were the levels of cell death as measured by PI staining (Figure 4h). Taken together, these data all support a role for autophagy in Dex-induced cell death in leukemic cells.

Akt dephosphorylation by Dex is involved in Dexinduced autophagy and cell death. PI3K/Akt signaling is a key pathway that negatively regulates autophagy. 8,27 Therefore, we investigated Akt phosphorylation status upon Dex treatment (Figure $5 \mathrm{a}$ and b). Strikingly, Dex treatment caused an almost complete dephosphorylation of Akt after $16 \mathrm{~h}$ as assessed by immunoblotting (Figure 5a) and after $24 \mathrm{~h}$ as assessed by flow cytometry (Figure $5 \mathrm{~b}$ ).

To investigate the relationship between Dex-induced Akt inactivation and the induction of autophagy and cell death,
RS4;11 cells were transiently co-transfected with a construct encoding a constitutively active $\mathrm{Akt}^{28}$ (Akt-DD) and GFP or GFP alone. Akt-DD protected from Dex-induced autophagosome formation, as measured by MDC staining in the GFPgated cells (Figure $5 \mathrm{c}$ ). We showed before that Dex-induced apoptosis is mediated through the activation of Bak, an event that correlated well with other apoptotic markers such as loss of mitochondrial membrane potential and re-distribution of plasma membrane phosphatidyl serines (Annexin Vpositivity). ${ }^{17}$ Therefore, we used stainings for active Bak to assess cell death and analyzed the amounts of Bak-positive cells in the gated GFP-positive population. Akt-DD significantly protected from Dex-induced Bak activation (Figure $5 d$ ). Thus, Dex-induced dephosphorylation of Akt is an upstream event triggering autophagy and subsequent cell death.

Dex induces PML protein and complex formation with Akt. The PML protein was shown to be a mediator of nuclear Akt inactivation. ${ }^{12}$ Therefore, we studied whether Dex affects $\mathrm{PML}$ expression. PML protein levels were induced in Dexsensitive lymphoid cell lines, RS4;11 (Figure 6a), SUP-B15 and 183E95 CLL, but not in the Dex-resistant Reh cells (not shown). Furthermore, PML was induced in Dex-sensitive but not in Dex-resistant primary CLL cells (Figure 6b and c). a
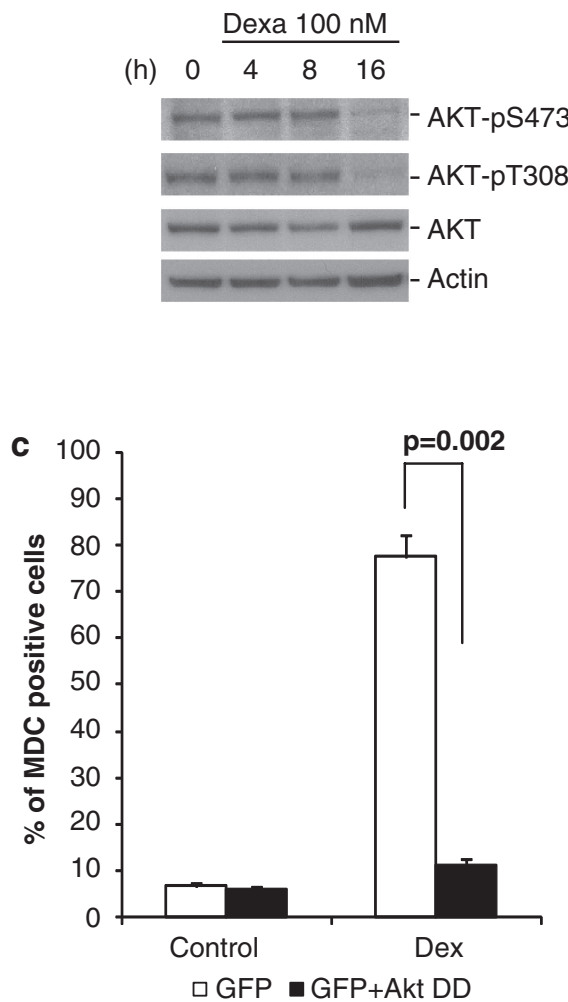
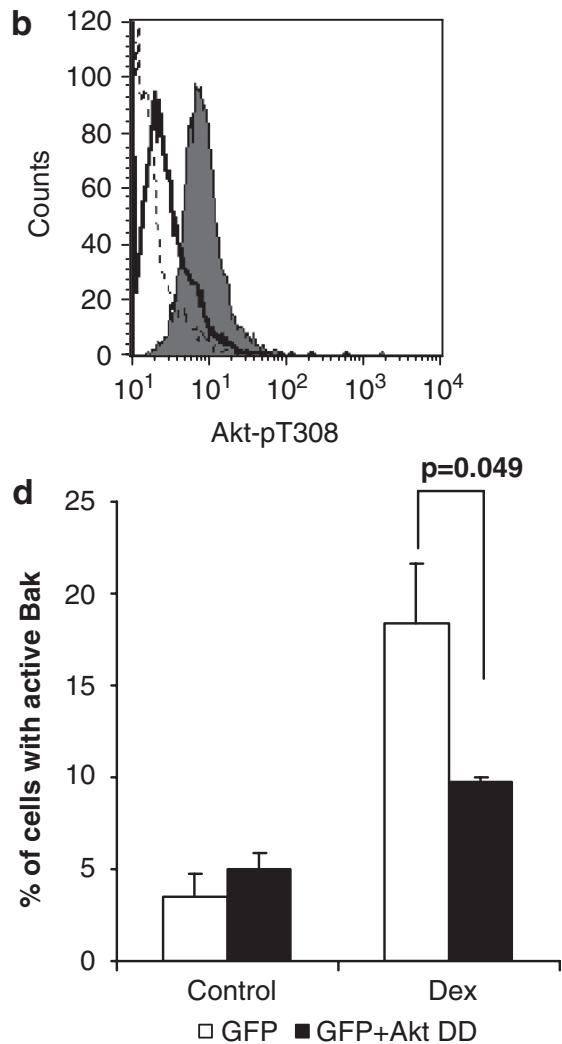

Figure 5 Dex-induced Akt dephosphorylation and requirement for autophagy and cell death. (a, b) Dex induces Akt dephosphorylation. RS4;11 cells were treated with $100 \mathrm{nM}$ of Dex and Akt phosphorylation status at Thr308 and Ser473 was assessed by immunoblotting at the indicated time points (a) and at the Thr-308 residue by immunostaining and flow cytometry at $24 \mathrm{~h}(\mathbf{b})$. Gray histogram: control cells; black punctuated line: negative control; black bold line: Dex-treated cells $(n=3)$. (c, d) Constitutively active Akt protects from Dex-induced autophagy and activation of Bak. RS4;11 cells were transfected with an expression construct encoding Akt double mutant (Akt DD), which mimics the effect of a constitutively phosphorylated Akt; autophagy was assessed by MDC staining and microscopy counting positive cells (c); and Bak activation - by immunostaining and flow cytometry $(n=3)(\mathbf{d})$ 
Statistical analysis showed a significant correlation between Dex-induced PML and cell death in primary ex vivo CLL cells (Figure 6d) further pointing to the importance of PML for Dex-induced cell death in lymphoid malignant cells. We next examined whether induction of PML leads to complex formation with Akt. Indeed, such complexes were first detected at $12 \mathrm{~h}$, peaked at $16 \mathrm{~h}$ and decreased at $24 \mathrm{~h}$ of Dex treatment (Figure 6e). We then took advantage of a recently developed technique, in situ proximity ligation assay, PLA, ${ }^{29}$ to confirm the interaction of PML and Akt in cells treated with Dex. The method is based on immunofluorescent staining using antibodies against two proteins of interest produced in different species; however, in contrast to a conventional double staining, the detection with secondary antibodies is based on a molecular technique where the signal will be amplified and detected only when the two secondary antibodies are localized in close proximity. ${ }^{29}$ Furthermore, with the use of the special software, BlobFinder (www.olink.se), the number of dots in the nucleus or cytoplasm can be quantified. In control RS4;11 cells, a limited number of PML and Akt molecules were colocalized (Figure 6f, red dots in control panel). Sixteen hours of Dex treatment led to a dramatic increase in the number of dots showing that Dex induced PML and Akt colocalization (Figure 6f, Dex 16 h panel). Furthermore, the colocalization between PML and Akt increased only in the nucleus, and not in the cytoplasm, showing that the interaction between the two proteins in response to Dex occurs in the nucleus (Figure 6f, bar chart).

PML plays an important role in Dex-induced cell death and Akt dephosporylation. We next evaluated the role of PML in Dex-induced cell death using thymocytes from PML knockout mice ${ }^{15}$ (Figure $7 a$ and $b$ ) and the silencing of PML expression in RS4;11 cells (Figure 7c-f). Mouse thymocytes WT and null for PML were treated with Dex for $18 \mathrm{~h}$ and analyzed for cell death (Figure 7a and b). WT thymocytes were significantly more sensitive to Dex as compared to human ALL cells, with $40 \%$ dying when $1 \mathrm{nM}$ of Dex was used. The absence of PML significantly decreased cell death in the range of Dex concentrations between 1 and $100 \mathrm{nM}$ (Figure $7 \mathrm{~b}$ ). This showed that PML is involved in Dexinduced cell death. Next, RS4;11 cells were transfected with siRNA against PML yielding $\sim 30 \%$ reduction in PML protein levels (Figure 7c). RS4;11 cells transfected with PML siRNA were partially protected against Dex-induced autophagy as assessed by MDC staining and GFP-LC3 translocation
(Figure 7d and e). Although western blotting for LC3-II as measure for autophagy could not be used in these experiments because of the low transfection efficiency of these cells, the data suggested that PML is involved in Dexinduced autophagy in leukemic cells. The RNA interference with PML expression also partially protected against Dexinduced cell death as measured by Annexin $\mathrm{V}$ staining, in line with the data on PML-/- thymocytes (Figure 7f). Together, these data show that PML plays an important role in Dexinduced cell death. As PML and Akt form complexes and colocalize in Dex-treated cells (Figure 6e,f), we next examined the role of PML in Dex-induced Akt dephosphorylation. Akt phosphorylation status at Thr-308 was assessed by flow cytometry, immunostainings and western blotting in cells transiently transfected with PML siRNA (Figures 7c, $g$ and $h$ ). Downregulation of PML levels using siRNA attenuated dephosphorylation of Akt as compared to lamin siRNA-transfected cells $24 \mathrm{~h}$ after Dex treatment by immunostaining and FACS (Figure $7 \mathrm{~g}$, left), also illustrated by microscopy (Figure $7 \mathrm{~g}$, right) and by western blotting (Figure $7 \mathrm{~h}$ ). These data suggest that PML plays an important role in the Dex-induced Akt dephosphorylation.

\section{Discussion}

Although GCs have been used in the treatment of lymphoid malignancies for more than 50 years, the actual mechanisms behind the induction of cell death have remained unclear. In this study we show that the GC Dex induces autophagy in lymphoid leukemia cells and that this induction plays an essential role in the process of cell death.

The identification of autophagy as a critical element in the action of GC was unexpected and, therefore, several experimental procedures were undertaken to validate this finding. The formation of the autophagic vesicles was shown by three independent approaches: electron microscopy, LC3-I to LC3-II conversion by western blotting and LC3 translocation to vacuoles in GFP-LC3-transfected cells as well as MDCstainings, which correlated well with the other autophagy markers. Furthermore, Dex treatment in the presence of lysosomal inhibitors led to an increased LC3-II conversion indicating that Dex enhanced formation of autophagosomes rather than decreased the rate of degradation of these transient vesicles. As we and others have shown that Dex induces a mitochondria-dependent apoptosis, ${ }^{17}$ the important question arises: what is the connection between autophagy

Figure 6 Dex induces PML protein and a complex formation with Akt. (a) RS4;11 cells were treated with $100 \mathrm{nM}$ of Dex for $36 \mathrm{~h}$, stained with an antibody against PML and analyzed by flow cytometry. Gray filled histogram: control; black solid line: Dex-treated cells. The chart represents the number of cells with 'high PML' in the M1 gate ( $n=3)$. (b, c) Ex vivo mononuclear cells from two CLL patients: sensitive (b) and resistant (c) were treated with $10 \mu \mathrm{M}$ Dex for $24 \mathrm{~h}$ and cell death was assessed by Annexin V/TMRE staining. The number of cells with 'high' PML in the gate M1 in $(\mathbf{b})$ increased from 19 to $39 \%(n=2)$. (d) Correlation of PML induction with cell death in primary CLL cells. Cells from nine patients sensitive ex vivo to Dex-induced cell death and from two resistant patients were analyzed for the induction of PML protein levels by Dex as exemplified in (b, c). Statistical analysis was carried out using Pearsons correlation $r=0.85$ ( $P$-value significant at 0.01 level). (e) Dex-induced complex formation between PML and Akt. RS4;11 cells were treated for the indicated time points and proteins were immunoprecipitated (IP) using anti-PML mAbs. Immune complexes were separated on PAGE and blotted with anti-Akt antibodies. Inputs correspond to $2 \%$ of total proteins used for IP. Lane 5 - negative control for IP with unrelated $\mathrm{mAb}(n=2)$. (f) Control and $100 \mathrm{nM}$ Dextreated for $16 \mathrm{~h} \mathrm{RS4;11} \mathrm{cells} \mathrm{were} \mathrm{cytospun} \mathrm{on} \mathrm{glass} \mathrm{slides,} \mathrm{stained} \mathrm{with} \mathrm{anti-PML} \mathrm{and} \mathrm{anti-Akt} \mathrm{antibodies} \mathrm{and} \mathrm{detected} \mathrm{using} \mathrm{proximity} \mathrm{ligation} \mathrm{assay,} \mathrm{PLA,} \mathrm{as} \mathrm{described} \mathrm{in}$ Materials and Methods section. Six Z-stack images were captured on a Zeiss Axioplan-2 microscope and Axiovision software 4.1. and processed through inverse filter deconvolution and extended focus, thus representing a two-dimensional illustration of the summary of all dots in each cell. BlobFinder software was used for the quantification $(n=3)$ (chart) 
and apoptosis during Dex-induced cell death. We observed that the formation of autophagosomes occurred early in the sequence of Dex-induced events, before Bak activation, loss of mitochondrial membrane potential and nuclear fragmentation. Furthermore, chemical and genetic inhibition of autophagosome formation led to a decrease in the apoptotic
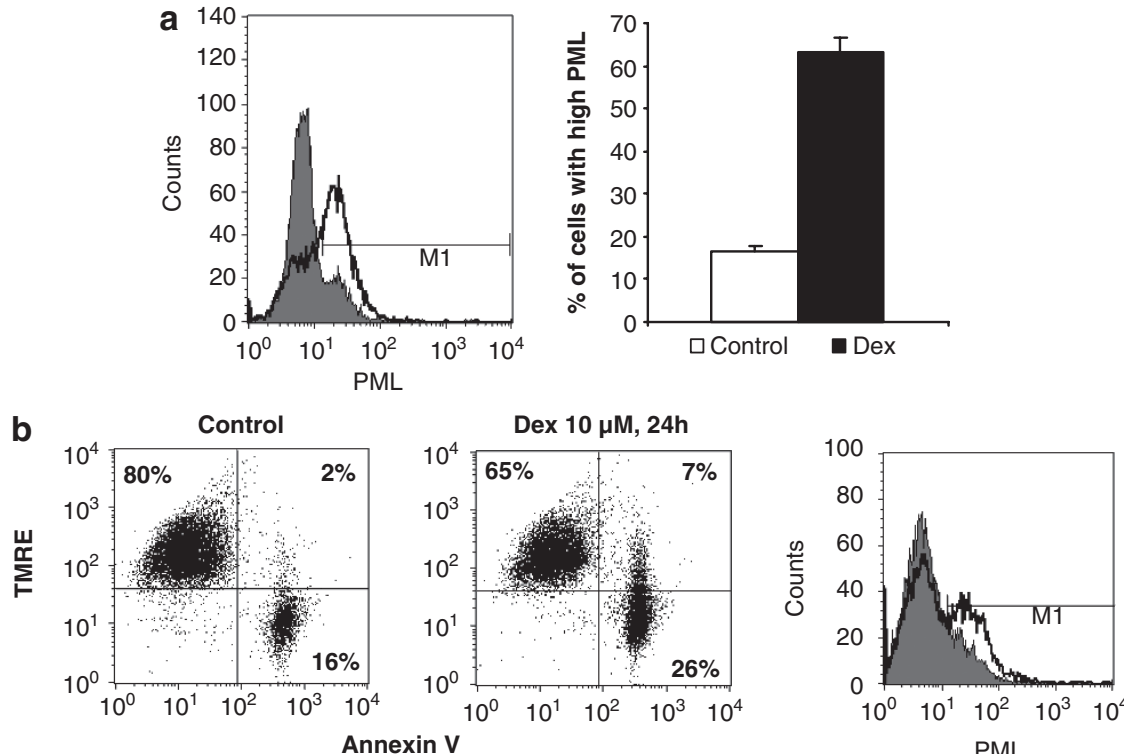

C

Annexin V

PML
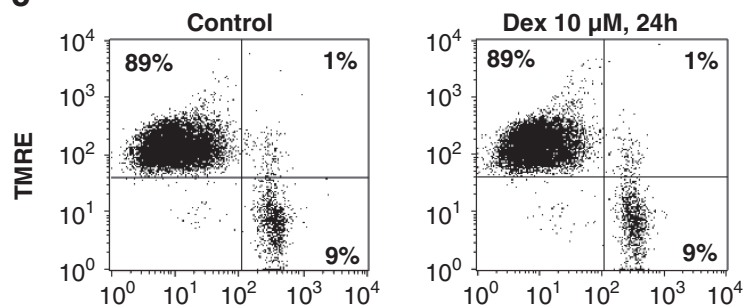

Annexin V
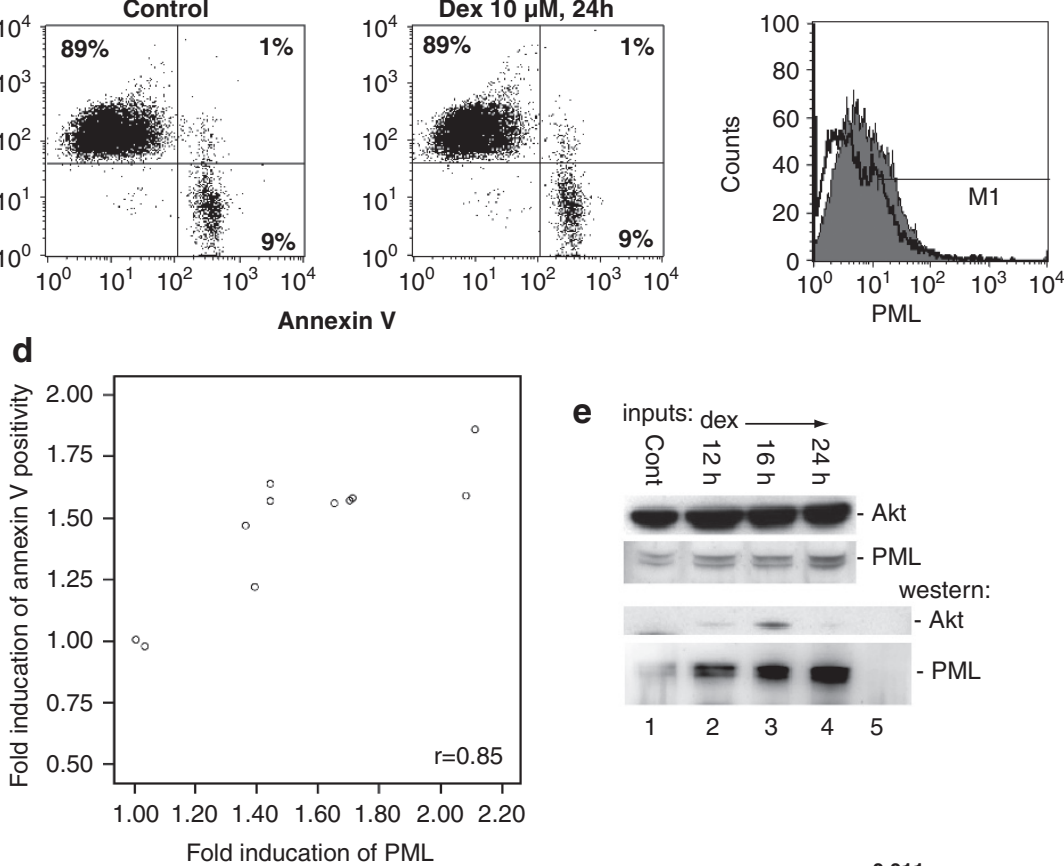

e

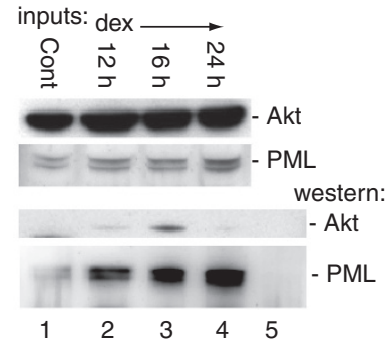

f

control

$\operatorname{dex} 16 \mathrm{~h}$
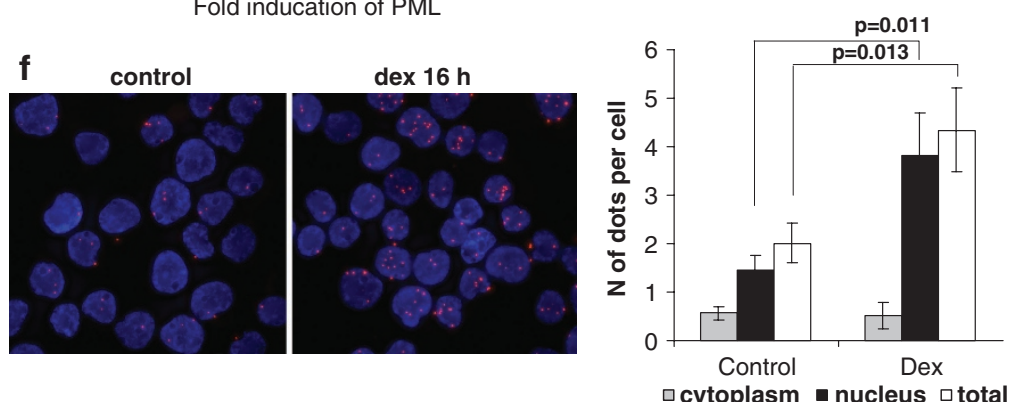
parameters, showing that Dex-induced autophagy not only lies upstream of apoptosis but is also required for the latter to occur. The relation between autophagy and apoptosis is complex. $^{8,26}$ The ongoing debate in the literature regarding the biological outcome of autophagy triggered by anticancer agents includes apparently conflicting data pointing to both a prosurvival role of autophagy and to autophagy as a cell death mechanism. ${ }^{6,30}$ Several of our current findings indicate that autophagy plays a crucial role in Dex-induced cell death in ALL cells. First, siRNA knockdown of Beclin 1 expression, a key regulator of autophagy, ${ }^{25}$ led to a decrease of both autophagy and cell death, pointing at the importance of autophagy in Dex-induced cell death. Second, inhibition of autophagy by the pharmacological inhibitors of PI3KIII led to a significant decrease of the hallmarks of apoptosis. 3-MA and Ly294002 block not only PI3KIII, that is a positive regulator of autophagy, but also PI3KI that through Akt and mTOR is a negative regulator of autophagy. However, the overall effect of these inhibitors is typically to block autophagy, because the class III enzymes act downstream of the class I enzymes. ${ }^{20}$ In addition, Dex potently inhibited Akt phosphorylation in ALL cells (see below); and rapamycin, an mTOR inhibitor, did not increase the level of autophagy or apoptosis induced by Dex (data not shown) suggesting that the same pathway is affected by Dex and the inhibitors of PI3KI/mTOR. Although it remains unclear exactly what governs the molecular switch between autophagy and apoptosis in the process of Dex-induced cell death, many of the proteins that were shown to regulate both autophagy and apoptosis are possible candidates ${ }^{8}$ including cleavage of Atg5, a protein required for autophagosome formation, whose cleaved form can induce cytochrome $c$ release and apoptosis. ${ }^{31}$ Thus, this study is the first to suggest a crucial importance of the process of autophagy for GC-induced cell death in human leukemic cells. It is noteworthy that another steroid hormone, ecdysone, has been shown to mediate development-associated cell death through autophagy during tissue remodeling in insect metamorphosis that is also associated with repression of $\mathrm{PI} 3 \mathrm{KI}$ signaling. ${ }^{32} \mathrm{~A}$ recent publication, however, argues that autophagy induced by Dex in a mouse $\mathrm{T}$ cell leukemia cell line transfected with $\mathrm{Bcl}-2$ has a protective effect on Dex-induced cells death. ${ }^{33}$ This contradiction might be a result of a differential, cell type-specific response to Dex. Interestingly, in the presence of caspase inhibitors, the autophagic features were preserved, suggesting that autophagy induced by Dex occurs upstream of apoptosis. ${ }^{33}$

We have also attempted to address the important question of what are the signals delivered by Dex that trigger autophagy? An earlier study by our group has shown that Dex-treatment causes downregulation of the antiapoptotic Bcl-2 family members Bcl-2 and Bcl-XL at the mRNA level. ${ }^{17}$ $\mathrm{Bcl}-2$ and $\mathrm{Bcl}-\mathrm{XL}$ have been found to interact with Beclin 1, and downregulation of $\mathrm{Bcl}-2$ was also found to trigger autophagy. ${ }^{34}$ Thus, the effect of Dex on Bcl-2 and Bcl-XL might presumably contribute to the induction of autophagy in human ALL cells. Another mechanism underlying induction of autophagy and supported by our findings in this study is the dephosphorylation of Akt. Akt is not only a wellknown inhibitor of apoptotic cell death, but it is also a major negative regulator of autophagy. ${ }^{8,27,30}$ Thus, inhibition of Akt might lead to the release of the break on autophagy and thereby initiate the autophagic process. Protection from Dexinduced autophagy by overexpression of a constitutively active Akt (Akt-DD) in our study confirmed this notion. Interestingly, although using very high concentrations of Dex, it was shown that Dex-treatment led to a nearly complete Akt dephosphorylation in a chondrocytic cell line. ${ }^{35}$ Although this was associated with apoptosis, it would be important to establish whether autophagy is induced by Dex in that system.

A question was next addressed of what underlies the mechanism of Dex-induced Akt inactivation. PML was recently shown to inactivate pAkt in the nucleus by specifically recruiting the Akt phosphatase PP2a and pAkt into the PODs, and $P M L$ loss lead to an increase in pAkt in vivo. ${ }^{12}$ We found in this study that Dex treatment lead to the complex formation between Akt and PML and their colocalization in the nucleus. Furthermore, the dephosphorylation of Akt by Dex treatment was dependent on the PML protein. PML was also required for Dex-induced apoptosis in normal and malignant lymphoid cells. Although showed on a limited number of patient samples, induction of PML significantly correlated with sensitivity to Dex, further strengthening the role of PML in Dex-induced cell death. Finally, our data suggest that PML is involved in the induction of autophagy by Dex in ALL cells. Taken together, our results provide a strong evidence for an important role of PML in Dex-induced cell death.

In conclusion, this study has identified that Dex-induced cell death is mediated through a PML and Akt-dependent activation of autophagy, which lies upstream of mitochondrial dysfunction and subsequent cell death. The identification of intracellular pathways critical for the efficacy of current chemotherapeutic treatments is one of the key objectives of current antitumor research. Thus, current findings may pave the way for future optimized use of GCs in the treatment of lymphoid malignancies.

Figure 7 PML is required for Dex-induced cell death, Akt dephosphorylation and autophagy. (a) Loss of PML suppresses Dex-induced apoptosis in primary mouse thymocytes. Cells from wild-type and pml-/- mice were cultured with the indicated dose of Dex for $18 \mathrm{~h}$, stained with Annexin V/PI and analyzed by flow cytometry. (b) Bar chart from wild-type and pml-/-mice data in (a) $(n=3)$. (c-f) Cells were transfected with siRNA against PML or Lamin and treated with $100 \mathrm{nM} \mathrm{Dex} \mathrm{for} 24 \mathrm{~h}(n=2)$. (c) PML protein levels were assessed by flow cytometry. Black dashed line - negative control; black solid line - PML siRNA; gray histogram - Lamin siRNA ( $n=2)$. (d) Autophagy was assessed by MDC staining and flow cytometry as in Figure 2c, MFI - mean fluorescence intensity $(n=2)$. (e) Cells were co-transfected with GFP-LC3 and siRNA against Lamin or PML and GFP-LC3 translocation was monitored by microscopy $(n=2)$. (f) Cell death in transfected with siRNA against PML or Lamin and treated with $100 \mathrm{nM}$ Dex RS4;11 cells was assessed by Annexin V staining and evaluated as a ratio between Annexin V positive Dex-treated cells to the corresponding controls. Mean of two independent experiments is shown. ( $\mathbf{g}-\mathbf{h})$ Akt phosphorylation at Thr 308 was evaluated in the untreated (control) and Dex-treated for $24 \mathrm{~h}$ RS4;11 cells transfected with siRNA against PML or Lamin, by immunostaining and flow cytometry $(n=2)(\mathbf{g}$, left: Gray histogram: untreated PML siRNA-transfected cells; black fine line: untreated Lamin siRNA-transfected cells; black bold line: Dex-treated Lamin siRNA-transfected cells; black dashed line: Dex-treated PML siRNA-transfected cells), microscopy ( $\mathbf{g}$, right: p-Thr308-Akt-red; nuclei - blue) and by immunoblotting (h). Chart represents quantification of p-Thr308-Akt band intensity in relation to the total protein levels 


\section{Materials and Methods}

Patients. The study included leukemic cells from two precursor-B ALL patients (2 boys, 13 and 16 years old), who were treated according to the NOPHO-ALL 2000 protocol, ${ }^{36,37}$ and from 11 patients ( 5 males, 6 females) with CLL for whom the median age was $77(50-85)$ years. The diagnosis was established according to the World Health Organization classification. ${ }^{38}$ All patients or their parents were informed of the investigative nature of this study, and informed consent was obtained from each patient/parent in accordance with the local ethical committee requirements (Stockholm, Sweden).

Statistical analysis. The statistical analysis for paired data was performed by Student's t-test. Spearman rank correlation (r) was used to investigate correlations between Dex-induced PML induction and cell death. $P$-values $<.05$ were a

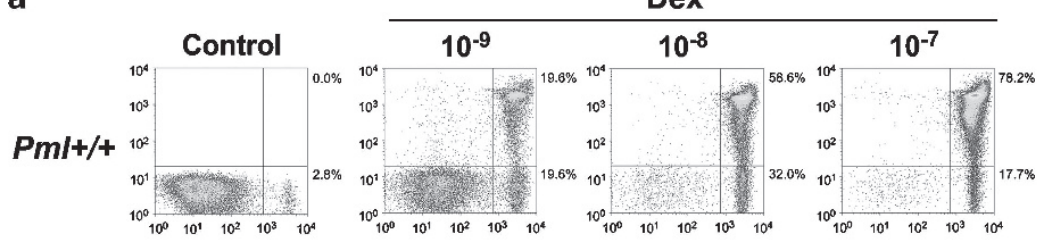

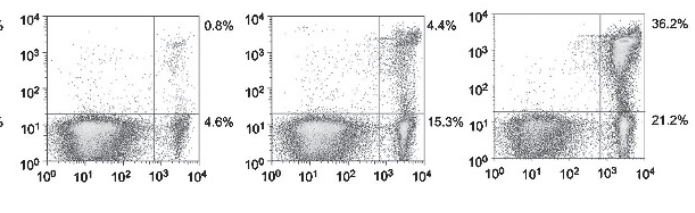

Annexin V

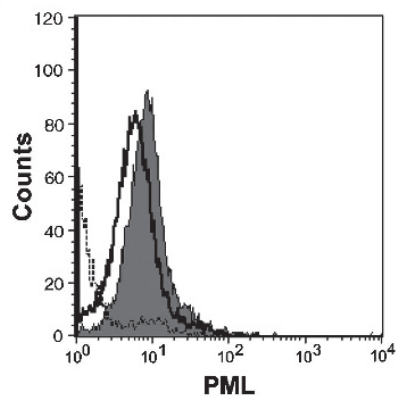

f

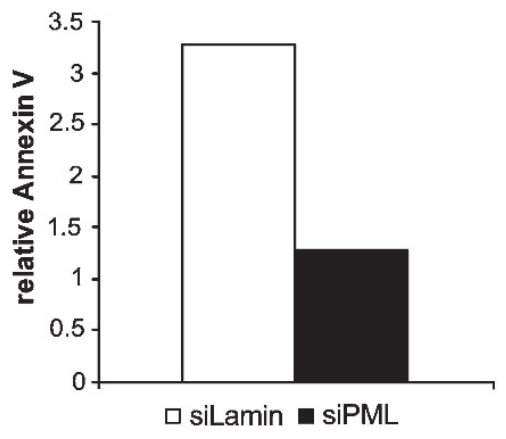

h

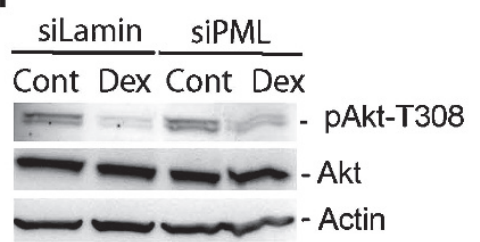

b

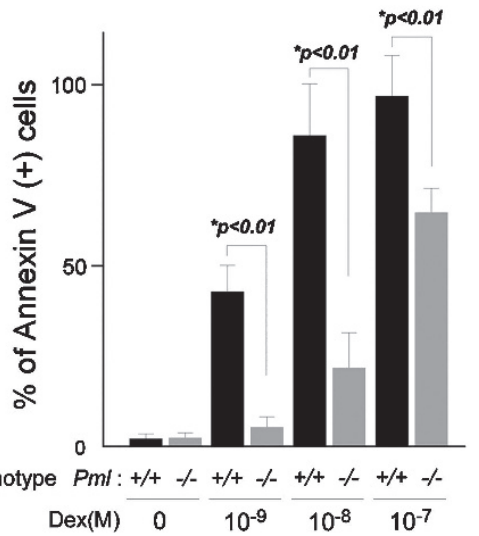

d

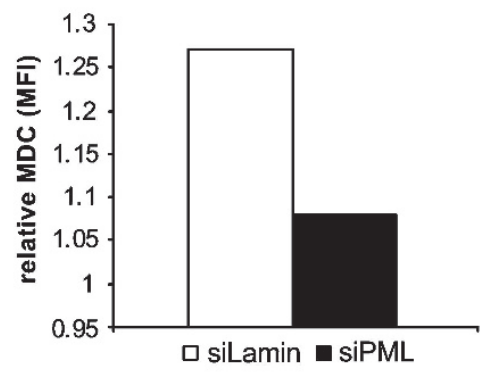

g

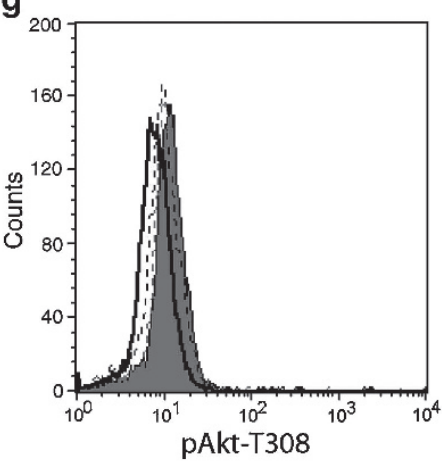

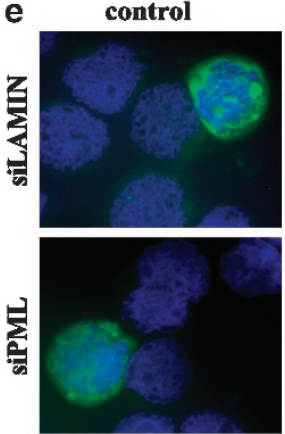

dex 24h
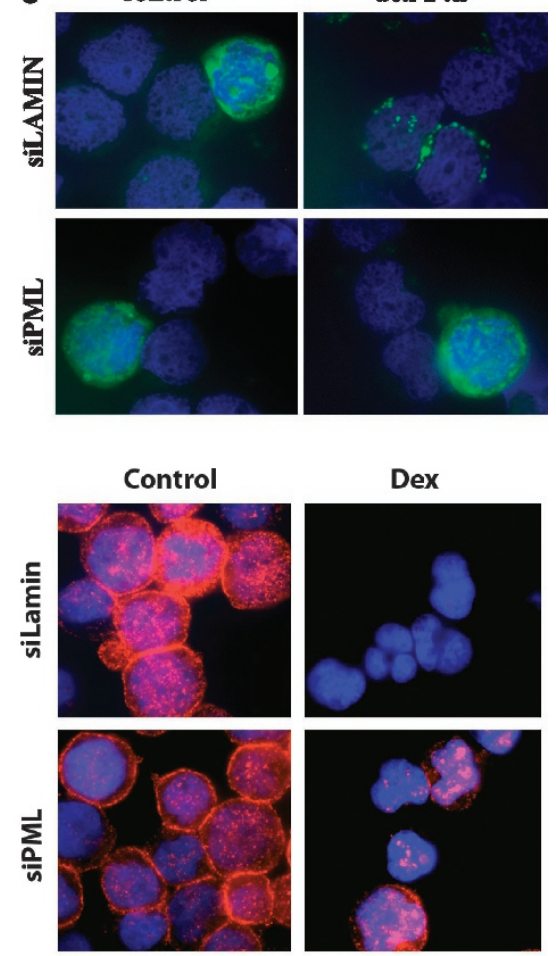

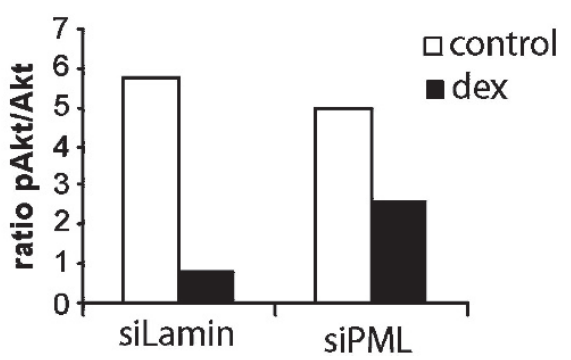


considered significant. All reported $P$-values are two-sided. All calculations were performed using the SPSS 12.0 (SPSS, Chicago, IL, USA) software.

Isolation and culture of primary cells. Mononuclear cells were isolated from bone marrow (ALL) or from peripheral blood (CLL) by centrifugation on a Ficoll/ Hypaque (Lymphoprep, Oslo, Norway) gradient and cryo-preserved in liquid nitrogen. Leukemic cells were cultured at a cell concentration of $2.5 \times 106 / \mathrm{ml}$ in RPMI 1640 culture medium supplemented with $10 \%$ heat-inactivated fetal bovine serum, $2 \mathrm{mM}$ L-glutamine, $50 \mu \mathrm{g} / \mathrm{ml}$ streptomycin, $50 \mu \mathrm{g} / \mathrm{ml}$ penicillin (GIBCO) and maintained in a humidified incubator in $5 \% \mathrm{CO}_{2}$ at $37^{\circ} \mathrm{C}$. Single cell suspensions of thymocytes derived from 4- to 5-week-old wild-type or pml-/mice ${ }^{15}$ were maintained in RPMI 1640 medium supplemented with glutamine, penicillin, and streptomycin and containing 10\% FBS and $50 \mathrm{mM}$ 2mercaptoethanol.

Cell lines, culture conditions and treatment. Four pre-B ALL cell lines, RS4;11 (ATCC, no.: CRL-1873, Manassas, USA), 697 (M Björkholm, Karolinska Institute, Sweden), Reh (ATCC) and SUP-B15 (German Collection of Microorganisms and Cell Cultures/DSMZ, no.: ACC 389, Germany) and 183E95 CLL cells (A Rosen, University of Linkoping, Sweden) were cultured in RPMI 1640 medium (GIBCO) (containing $25 \mathrm{mM}$ Hepes for the RS4;11, 697 and SUP-B15 cell lines), supplemented with $10 \%$ (v/v) heat-inactivated fetal bovine serum, $2 \mathrm{mM}$ L-glutamine, $50 \mu \mathrm{g} / \mathrm{ml}$ streptomycin and penicillin (GIBCO) and maintained in a humidified incubator in $5 \% \mathrm{CO}_{2}$ at $37^{\circ} \mathrm{C}$. A quantatity of $200 \mathrm{nM}$ of Dex (Oradexon $5 \mathrm{mg} / \mathrm{ml}$ water solution, Oy Organon $A B$, Finland) was used

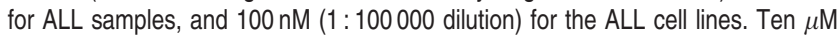
of Dex was used for the CLL samples to induce cell death, as was reported before. ${ }^{23}$ Amino-acid starvation was performed by incubating cells in EBSS medium (Sigma-Aldrich Sweden $\mathrm{AB}$ ) for $2-4 \mathrm{~h}$ to induce autophagy. Experiments were performed at least three times if not otherwise stated. Error-bars represent S.D.

Inhibitors and antibodies. The PI3K inhibitor LY294002 was used at $5 \mu \mathrm{M}$, 3-methyladenine (3-MA) was used at $5 \mathrm{mM}$, lysosomal inhibitors, monensin - at 1 and $10 \mu \mathrm{M}$ and bafilomycin $\mathrm{A} 1$ - at 10 and $100 \mathrm{nM}$ and chloroquine at 10 and $50 \mu \mathrm{M}$ (Sigma-Aldrich Sweden $\mathrm{AB}$ ). The mouse monoclonal antibody, mAb, against active Bax, clone $6 \mathrm{~A}$, against $\mathrm{Bcl}-2$ (cat. 554160), Bcl-xL (cat. 610212) and against Beclin 1 was from Pharmingen. The mAb against active Bak, AM03, clone TC100, was from Oncogene Research Products (San Diego, CA, USA). The rabbit serum against phospho-Thr308-Akt, Akt and LC3B were from Cell Signaling (In vitro Sweden $A B$, Sweden). The mAbs against human PML were from Santa Cruz Biotechnology, Inc. (Santa Cruz, CA, USA) and against mouse PML from Upstate (Millipore); rabbit polyclonal serum against PML was from Chemicon Int. The allophycocyanin-conjugated goat anti-mouse $\mathrm{Ig}$ was from Pharmingen and flourescein isothiocyanate-conjugated swine anti-rabbit from DakoCytomation (Glostrup, Denmark). The Alexa Fluor 594 goat anti-rabbit IgG was from Molecular Probes Inc. (Eugene, OR, USA).

Assessment of apoptosis and immunostainings for flow cytometry. Apoptosis was assessed using either Annexin V FLUOS (Roche Diagnostics Gmbh, Mannheim, Germany), Annexin V/PI double staining (BD Pharmingen) or Annexin V/TMRE (TMRE; Molecular Probes Inc.) double stainings, and for active Bak or Bax as described earlier. ${ }^{39}$ Only PI staining was performed when GFP-positive transfected cell population was gated in FL1, and analyzed in FL3. Stainings were analyzed by FACS Calibur flow cytometer (Becton Dickinson (BD), San José, CA, USA) using Cell Quest software (BD). For quantification of monodansylcadaverine, MDC, staining, cells were incubated with $0.05 \mathrm{mM} \mathrm{MDC}$ at $37^{\circ} \mathrm{C}$ for $1 \mathrm{~h}$, washed with PBS and acquired on an LSR II Becton Dickinson flow cytometer equipped with a $355 \mathrm{~nm}$ UV laser. Data were analyzed, and mean fluorescence intensity (MFI) values calculated, using the FlowJo software (Flow Jo, Tree Star Inc., CR, USA).

Immunostainings for fluorescent microscopy. The active Bax staining was performed as described earlier. ${ }^{39}$ The pAkt Thr308 staining was performed according to the manufacturer's instructions. Slides were mounted using Vectashield with DAPI (Vector Lab. Inc.). For labeling and visualization of MDC labeled vacuoles, cells were fixed in $3 \%$ PFA and mounted using Vectashield without DAPI or with 1:10 diluted Vectashield with DAPI. The images were recorded on a Zeiss Axioplan-2 microscope with a Zeiss dual mode cooled CCD camera and Axiovision software 4.1. A special UV filter was used for the detection of MDC staining with excitation at $350 \pm 50 \mathrm{~nm}$ and emission at $420 \mathrm{~nm}$. The images were further processed using Photoshop software (Adobe Systems Inc.).

The Duolink reagent for the in situ Proximity Ligation Assay, PLA, was obtained from Olink Bioscience (Uppsala, Sweden). Briefly, cells were cytospun on glass slides, fixed and stained using anti-PML mAb and rabbit serum against Akt. The slides were then incubated with secondary antibodies linked to oligonucleotides-proximity probes. Their ligation would lead to a formation of circle DNA that will serve as a template in rolling circle amplification. These procedures and the detection were performed according to the manufacturer's instructions. The controls included stainings where either one or the other primary antibody was omitted. Images were captured using zstacks and deconvolution with inverse filter mode. As the cells are three-dimensional, the mode 'extended focus' was applied to summarize all the dots in a two-dimensional image. For the quantification, the BlobFinder software supplied by Olink (http:// www.cb.uu.se/ amin/BlobFinder/) was used.

Western blotting and immunoprecipitation. For western blot analysis, cells were lysed and protein concentration was quantified as described. ${ }^{40}$ Thirty to 40 microgram of protein was loaded for SDS-PAGE. The membranes were incubated overnight at $+4^{\circ} \mathrm{C}$ with appropriate primary antibody. $\beta$-actin or $\beta$-tubulin (Sigma-Aldrich Sweden AB) were used as loading control. Secondary peroxidase-conjugated anti-mouse or anti-rabbit antibodies were from Cell Signaling. Bands were visualized by SuperSignal West Pico chemiluminescent substrate (Pierce) according to the manufacturer's protocol. The images were captured using an LAS-1000 from Fujfilm. Quantification of the band intensity was performed using Image Gauge, Fujifilm. For immunoprecipitation, IP, cells were lysed in IP buffer (1\% Triton X-100, $40 \mathrm{mM}$ Hepes, pH 7.5, $120 \mathrm{mM} \mathrm{NaCl}$, $1 \mathrm{mM}$ EDTA, $2,5 \mathrm{mM}$ sodium pyrophosphate and sodium orthovanadate, $10 \mathrm{mM}$ glycerophosphate, $10 \mathrm{mM} \mathrm{NaF}$ (all from Sigma-Aldrich Sweden $\mathrm{AB}$ ) and protease inhibitor cocktail from Roche 1:100), and $1 \mathrm{mg}$ of proteins were subjected to IP with anti-PML mAbs overnight. After incubation with protein G-coated beads (GammaBind G Sepharose, GE Healthcare) and washes, proteins captured on the beads were separated on PAGE and western was performed using anti-Akt or anti-PML rabbit serum.

Transmission electron microscopy. RS4;11 cells were incubated with Dex $100 \mathrm{nM}$ for 24 and $36 \mathrm{~h}$. After indicated times cells were harvested and processed as described. ${ }^{41}$ Micrographs were taken at 2000-2500 $\times$ magnification and printed copies were used for evaluation.

Constructs, siRNA and transfections. CMV5-HA PKB $\alpha$ T308D/S437D (Akt DD), encoding PKB/Akt with mutations that mimic the effect of phosphorylation at corresponding residues, was a kind gift from Dr. DR Alessi at the University of Dundee, Dundee, Scotland, UK. ${ }^{28}$ GFP-LC3 was a kind gift from Dr. N Mizushima at the Tokyo Metropolitan Institute of Medical Science, Tokyo, Japan and Dr. T Yoshimori at the National Institute of Genetics, Tokyo, Japan. ${ }^{18}$ RS4;11 cells $\left(4 \times 10^{6}\right)$ were co-transfected with 7.5 or $5 \mu \mathrm{g}$ of plasmids by Amaxa nucleofection (Reactionlab Sverige AB, Uppsala, Sweden), using solution R, program X-01 according to the manufacturer's instructions. Following the transfection, cells were plated in $2 \mathrm{ml}$ of growth medium and cultured for $24 \mathrm{~h}$ and then treated with $100 \mathrm{nM}$ of Dex for the indicated time. siRNA against Lamin (cat. D-001050-01-05), siRNA against GFP (cat. P-002048-01-20) and siRNA corresponding to the following CDNA sequence $5^{\prime}$-CAGTTTGGCACAATCAATA-3' for Beclin 1 were purchased from Dharmacon (Lafayette, CO, USA). The siRNA $5^{\prime}$-GAGUCGGCCGACUUCUG GU(dTdT)-3 for PML was purchased from MWG-Biotech AG (Ebersberg, Germany). For siRNA transfections, RS4;11 cells $\left(4 \times 10^{6}\right)$ were electroporated using Amaxa nucleofection. Cells were immediately diluted in $2 \mathrm{ml}$ of growth medium and cultured for $48 \mathrm{~h}$ for further treatments and analysis. Final concentration of $5-20 \mathrm{nM}$ of siRNA against Beclin 1 or $60 \mathrm{nM}$ of siRNA against PML was used. The same amount of siRNA against lamin was used as control. Co-transfection with GFP was used together with Akt DD or Beclin 1 siRNA for cell death and autophagy assessment. Cell death was assessed as PI positivity in GFP-gated cells or by Annexin V staining in total populations analyzed by flow cytometry. Autophagosome formation was assessed by MDC staining in the total or the GFP-positive cell population by microscopy or FACS. Transfection efficacy according to GFP gating varied between 2 and $9 \%$.

Acknowledgements. We thank Dr. DR Alessi at the University of Dundee, Dundee, Scotland, UK for the kind gift of the CMV5-HA PKB $\alpha$ T308D/S437D 
plasmid, Dr. N Mizushima at the Tokyo Metropolitan Institute of Medica Science, Tokyo, Japan and Dr. T Yoshimori at the National Institute of Genetics, Mishima-Shizouka, Japan for the kind gift of the GFP-LC3 plasmid. This study was supported by grants from the Swedish Child Cancer Society, The Cancer Society of Stockholm, the Swedish Cancer Society, the Swedish Research Council and the Swedish Society for Medical Research.

1. Gaynon PS, Carrel AL. Glucocorticosteroid therapy in childhood acute lymphoblastic leukemia. Adv Exp Med Biol 1999; 457: 593-605.

2. Greenstein S, Ghias K, Krett NL, Rosen ST. Mechanisms of glucocorticoid-mediated apoptosis in hematological malignancies. Clin Cancer Res 2002; 8: 1681-1694.

3. Kaspers GJ, Pieters R, Van Zantwijk CH, Van Wering ER, Van Der Does-Van Den Berg A Veerman AJ. Prednisolone resistance in childhood acute lymphoblastic leukemia: vitro-vivo correlations and cross-resistance to other drugs. Blood 1998; 92: 259-266.

4. Schrappe M, Reiter A, Zimmermann M, Harbott J, Ludwig WD, Henze G et al. Long-term results of four consecutive trials in childhood ALL performed by the ALL-BFM study group from 1981 to 1995. Berlin-Frankfurt-Munster. Leukemia 2000; 14: 2205-2222.

5. Distelhorst CW. Recent insights into the mechanism of glucocorticosteroid-induced apoptosis. Cell Death Differ 2002; 9: 6-19.

6. Gozuacik D, Kimchi A. Autophagy as a cell death and tumor suppressor mechanism Oncogene 2004; 23: 2891-2906.

7. Jaattela M. Multiple cell death pathways as regulators of tumour initiation and progression. Oncogene 2004; 23: 2746-2756.

8. Gozuacik D, Kimchi A. Autophagy and cell death. Curr Top Dev Biol 2007; 78: 217-245.

9. Aita VM, Liang XH, Murty VV, Pincus DL, Yu W, Cayanis E et al. Cloning and genomic organization of beclin 1, a candidate tumor suppressor gene on chromosome 17q21. Genomics 1999; 59: 59-65.

10. Petiot A, Ogier-Denis E, Blommaart EF, Meijer AJ, Codogno P. Distinct classes of phosphatidylinositol $3^{\prime}$-kinases are involved in signaling pathways that contro macroautophagy in HT-29 cells. J Biol Chem 2000; 275: 992-998.

11. Botti J, Djavaheri-Mergny M, Pilatte Y, Codogno P. Autophagy signaling and the cogwheels of cancer. Autophagy 2006; 2: 67-73.

12. Trotman LC, Alimonti A, Scaglioni PP, Koutcher JA, Cordon-Cardo C, Pandolfi PP Identification of a tumour suppressor network opposing nuclear Akt function. Nature 2006; 441: 523-527.

13. Bernardi R, Pandolfi PP. Role of PML and the PML-nuclear body in the control of programmed cell death. Oncogene 2003; 22: 9048-9057.

14. Wang ZG, Delva L, Gaboli M, Rivi R, Giorgio M, Cordon-Cardo C et al. Role of PML in cell growth and the retinoic acid pathway. Science 1998; 279: 1547-1551.

15. Wang ZG, Ruggero D, Ronchetti S, Zhong S, Gaboli M, Rivi R et al. PML is essential for multiple apoptotic pathways. Nat Genet 1998; 20: 266-272

16. Quignon F, De Bels F, Koken M, Feunteun J, Ameisen JC, de The H. PML induces a nove caspase-independent death process. Nat Genet 1998; 20: 259-265.

17. Laane E, Panaretakis T, Pokrovskaja K, Buentke E, Corcoran M, Soderhall S et al. Dexamethasone-induced apoptosis in acute lymphoblastic leukemia involves differential regulation of Bcl-2 family members. Haematologica 2007; 92: 1460-1469.

18. Kabeya Y, Mizushima N, Ueno T, Yamamoto A, Kirisako T, Noda T et al. LC3, a mammalian homologue of yeast Apg8p, is localized in autophagosome membranes after processing. EMBO J 2000; 19: 5720-5728.

19. Mizushima N, Yoshimori T. How to interpret LC3 immunoblotting. Autophagy 2007; 3 542-545.

20. Klionsky DJ, Abeliovich H, Agostinis P, Agrawal DK, Aliev G, Askew DS et al. Guidelines fo the use and interpretation of assays for monitoring autophagy in higher eukaryotes. Autophagy 2008; 4: 151-175.
21. Fass E, Shvets E, Degani I, Hirschberg K, Elazar Z. Microtubules support production of starvation-induced autophagosomes but not their targeting and fusion with lysosomes. J Biol Chem 2006; 281: 36303-36316.

22. Iwai-Kanai E, Yuan H, Huang C, Sayen MR, Perry-Garza CN, Kim L et al. A method to measure cardiac autophagic flux in vivo. Autophagy 2008; 4: 322-329.

23. Bellosillo B, Villamor N, Lopez-Guillermo A, Marce S, Bosch F, Campo $E$ et al. Spontaneous and drug-induced apoptosis is mediated by conformational changes of Bax and Bak in B-cell chronic lymphocytic leukemia. Blood 2002; 100: 1810-1816.

24. Blommaart EF, Krause U, Schellens JP, Vreeling-Sindelarova H, Meijer AJ. The phosphatidylinositol 3-kinase inhibitors wortmannin and LY294002 inhibit autophagy in isolated rat hepatocytes. Eur J Biochem 1997; 243: 240-246.

25. Liang XH, Jackson S, Seaman M, Brown K, Kempkes B, Hibshoosh $\mathrm{H}$ et al. Induction of autophagy and inhibition of tumorigenesis by beclin 1. Nature 1999; 402: 672-676.

26. Maiuri MC, Zalckvar E, Kimchi A, Kroemer G. Self-eating and self-killing: crosstalk between autophagy and apoptosis. Nat Rev Mol Cell Biol 2007; 8: 741-752.

27. Klionsky DJ, Emr SD. Autophagy as a regulated pathway of cellular degradation. Science 2000; 290: 1717-1721.

28. Alessi DR, Andjelkovic M, Caudwell B, Cron P, Morrice N, Cohen P et al. Mechanism of activation of protein kinase B by insulin and IGF-1. EMBO J 1996; 15: 6541-6551.

29. Soderberg O, Gullberg M, Jarvius M, Ridderstrale K, Leuchowius KJ, Jarvius J et al. Direct observation of individual endogenous protein complexes in situ by proximity ligation. Nat Methods 2006; 3: 995-1000.

30. Kondo $Y$, Kanzawa $T$, Sawaya $R$, Kondo $S$. The role of autophagy in cancer development and response to therapy. Nat Rev Cancer 2005; 5: 726-734.

31. Yousefi S, Perozzo R, Schmid I, Ziemiecki A, Schaffner T, Scapozza L et al. Calpain-mediated cleavage of Atg5 switches autophagy to apoptosis. Nat Cell Biol 2006; 8: 1124-1132

32. Rusten TE, Lindmo K, Juhasz G, Sass M, Seglen PO, Brech A et al. Programmed autophagy in the Drosophila fat body is induced by ecdysone through regulation of the PI3K pathway. Dev Cell 2004; 7: 179-192.

33. Swerdlow S, McColl K, Rong Y, Lam M, Gupta A, Distelhorst CW. Apoptosis inhibition by $\mathrm{Bcl}-2$ gives way to autophagy in glucocorticoid-treated lymphocytes. Autophagy 2008; 4: $1-9$.

34. Saeki K, Yuo A, Okuma E, Yazaki Y, Susin SA, Kroemer G et al. Bcl-2 down-regulation causes autophagy in a caspase-independent manner in human leukemic HL60 cells. Cell Death Differ 2000; 7: 1263-1269.

35. Chrysis D, Zaman F, Chagin AS, Takigawa M, Savendahl L. Dexamethasone induces apoptosis in proliferative chondrocytes through activation of caspases and suppression of the Akt-phosphatidylinositol 3 '-kinase signaling pathway. Endocrinology 2005; 146: 1391-1397.

36. Gustafsson G, Schmiegelow K, Forestier E, Clausen N, Glomstein A, Jonmundsson G et al. Improving outcome through two decades in childhood ALL in the Nordic countries: the impact of high-dose methotrexate in the reduction of CNS irradiation. Nordic Society of Pediatric Haematology and Oncology (NOPHO). Leukemia 2000; 14: 2267-2275

37. Schmiegelow K, Gustafsson G. Acute Lymphoblastic leukemia In: PA V (ed). Cancer in Chidlren. Clinical Management. Fifth Edition. Oxford University Press: Oxford, 2005.

38. Jaffe ES, Harris NL, Stein H, Vardiman JW (eds.). World Health Organization Classification of Tumours. Pathology and Genetics of Tumours of Haematopoietic and Lymphoid Tissues. IARC Press: Lyon, 2001.

39. Panaretakis T, Pokrovskaja K, Shoshan MC, Grander D. Activation of Bak, Bax, and BH3-only proteins in the apoptotic response to doxorubicin. J Biol Chem 2002; 277 : 44317-44326.

40. Thyrell L, Erickson S, Zhivotovsky B, Pokrovskaja K, Sangfelt O, Castro J et al. Mechanisms of Interferon-alpha induced apoptosis in malignant cells. Oncogene 2002; 21: 1251-1262.

41. Hansson A, Hance N, Dufour E, Rantanen A, Hultenby K, Clayton DA et al. A switch in metabolism precedes increased mitochondrial biogenesis in respiratory chain-deficient mouse hearts. Proc Natl Acad Sci USA 2004; 101: 3136-3141. 